\title{
Nonparametric Estimation of Education Productivity with an Application to Dutch Schools
}

Citation for published version (APA):

Brennan, S., Haelermans, C., \& Ruggiero, J. (2014). Nonparametric Estimation of Education Productivity with an Application to Dutch Schools. European Journal of Operational Research, 234(3), 809. https://doi.org/10.1016/j.ejor.2013.10.030

Document status and date:

Published: 01/01/2014

DOI:

10.1016/j.ejor.2013.10.030

Document Version:

Publisher's PDF, also known as Version of record

Document license:

Taverne

Please check the document version of this publication:

- A submitted manuscript is the version of the article upon submission and before peer-review. There can be important differences between the submitted version and the official published version of record.

People interested in the research are advised to contact the author for the final version of the publication, or visit the DOI to the publisher's website.

- The final author version and the galley proof are versions of the publication after peer review.

- The final published version features the final layout of the paper including the volume, issue and page numbers.

Link to publication

\footnotetext{
General rights rights.

- You may freely distribute the URL identifying the publication in the public portal. please follow below link for the End User Agreement:

www.umlib.nl/taverne-license

Take down policy

If you believe that this document breaches copyright please contact us at:

repository@maastrichtuniversity.nl

providing details and we will investigate your claim.
}

Copyright and moral rights for the publications made accessible in the public portal are retained by the authors and/or other copyright owners and it is a condition of accessing publications that users recognise and abide by the legal requirements associated with these

- Users may download and print one copy of any publication from the public portal for the purpose of private study or research.

- You may not further distribute the material or use it for any profit-making activity or commercial gain

If the publication is distributed under the terms of Article $25 \mathrm{fa}$ of the Dutch Copyright Act, indicated by the "Taverne" license above, 
Innovative Applications of O.R.

\title{
Nonparametric estimation of education productivity incorporating nondiscretionary inputs with an application to Dutch schools
}

\author{
Shae Brennan ${ }^{\mathrm{a}}$, Carla Haelermans ${ }^{\mathrm{b}, \mathrm{c}}$, John Ruggiero ${ }^{\mathrm{a}, *}$ \\ ${ }^{a}$ University of Dayton, United States \\ b TIER, Maastricht University, The Netherlands \\ ${ }^{\mathrm{c}}$ Delft University of Technology, The Netherlands
}

\section{A R T I C L E I N F O}

\section{Article history:}

Received 28 May 2013

Accepted 11 October 2013

Available online 23 October 2013

\section{Keywords:}

Data Envelopment Analysis

Malmquist productivity

Education

\begin{abstract}
A B S T R A C T
In this paper we develop a Malmquist productivity index for public sector production characterized by the influence of environmental variables. We extend Johnson and Ruggiero (2011) to the more general case of variable returns to scale to further decompose the Malmquist productivity index into technical, efficiency, scale and environmental change. We apply our model to analyze productivity of Dutch schools using 2002-2007 data. The results indicate that the environment influences the productivity index as well as the technical, efficiency, scale and environmental change components. We see that schools with a moderate classification of environment have the highest productivity numbers. In line with expectations, schools with the worst environment also perform worse and would perform better with an improved environment.
\end{abstract}

(c) 2013 Elsevier B.V. All rights reserved.

\section{Introduction}

Public sector service provision has been modeled as a production process where discretionary inputs are transformed into outcomes of interest to the community. For example, in education, schools employ teachers, administrators and capital to produce desirable outcomes (including standardized test scores). The outcomes achievable, however, depend on the operating environment that a producing unit operates under. Often in the public sector, production is influenced by exogenous factors. In education, the outcomes achieved are influenced by student (intelligence), family (income and parental education) and community (poverty) socioeconomic conditions. Bradford, Malt, and Oates (1969) provided a formal economic model of public sector production where outcome provision is determined by local government service provision and the socioeconomic factors. In education, there is clear evidence that student achievement is influenced by student and family characteristics; see Hanushek (1979, 1986). The production process of education, while incorporating these student and family characteristics is often analyzed using Data Envelopment Analysis.

Data Envelopment Analysis (DEA) is a nonparametric programming approach to analyze production and efficiency devel-

* Corresponding author. Address: 509 Miriam Hall, Dayton, OH 45469-2251, United States. Tel.: +1 9372292550.

E-mail address: jruggiero1@udayton.edu (J. Ruggiero). oped by Charnes, Cooper, and Rhodes (1978) and Banker, Charnes, and Cooper (1984) under the assumption of constant and variable returns to scale, respectively. The model has proven useful not only because it is nonparametric but also because it allows multiple inputs and outputs. DEA has economic production as its foundation. Farrell (1957) showed that input isoquants could be approximated with piecewise linear segments with overall inefficiency decomposed into technical and allocative parts. Farrell and Fieldhouse (1962) extended Farrell's work by relaxing the assumption of constant returns to scale and suggesting linear programming as a tool for efficiency measurement. Boles (1971) extended these models to variable returns to scale. There have been many useful theoretical extensions; Färe and Lovell (1978) provided the non-radial Russell measure and Banker and Morey (1986a, 1986b) allowed categorical and nondiscretionary variables and Ruggiero (1996b) allowed environmental variables. ${ }^{1}$

Today, the application of DEA to the educational sector is very common. Recent studies applying DEA to education include Mancebón, Calero, Choi, and Ximénez-de-Embún (2012), Haelermans and Ruggiero (2013), Johnes, Bradley, and Little (2012) and Essid, Ouellette, and Vigeant (2013), Essid, Ouellette, and Vigeant (2014), among others. More established non-parametric work in

\footnotetext{
1 These public sector models used to control for nondiscretionary inputs can also be applied to private sector applications where factors of production are fixed. For example, if the analysis is the short-run with capital fixed, capital can be treated as a nondiscretionary input.
} 
the educational sector is, among others, written by Haelermans and De Witte (2012), Kirjavainen and Loikkanen (1998), De Witte, Rogge, Cherchye, and van Puyenbroeck (2012), Joumady and Ris (2005), Oliveira and Santos (2005) and Ruggiero (1996a).

While DEA is primarily used to measure technical and scale efficiency, it has also been used to analyze productivity using multiple time periods. Caves, Christensen, and Diewert (1982) introduced the Malmquist productivity index as the geometric mean of distance functions. This allowed measurement of productivity growth and technical change using index numbers. Färe, Grosskopf, Lindgren, and Roos (1992) and Färe, Grosskopf, Norris, and Zhang (1994) developed a nonparametric estimator of the Malmquist productivity index under the assumption of constant returns to scale and provided a decomposition into technical and efficiency change. Ray and Desli (1997) developed a further decomposition under a variable returns to scale technology to allow scale efficiency change. ${ }^{2}$ Johnson and Ruggiero (2011) extended the Färe, Grosskopf, Norris, and Zhang (1994) decomposition public sector applications using the conditional convexity model of Ruggiero (1996b) as a base. This allowed a further decomposition of overall productivity with an additional component capturing the influence of the environment. These productivity models also have led to many applications in the educational sector (e.g. Essid, Ouellette, \& Vigeant, 2014; Ouellette \& Vierstraete, 2010; Parteka \& WolszcakDerlacz, 2012). For the agricultural sector, O'Donnell (2012), developed and applied a total factor productivity index which is completely consistent with all relevant axioms from index theory. O'Donnell provides a decomposition that includes technical change, technical efficiency, scale efficiency and mix efficiency changes. Unlike O'Donnell (2012), we do not have output prices and therefore estimate the Malmquist index and its associated components. In addition, O'Donnell (2012) analyzes agricultural production while we focus more heavily on the environmental index given our application to the public sector. ${ }^{3}$

In education, an increase in productivity could result not only from changes in technical and scale efficiency and technical progress, but also from changes in the exogenous environment. With student mobility, for example, a school might realize better outcomes from having students from a better socioeconomic environment. The main contribution of this paper is that we extend the Johnson and Ruggiero (2011) decomposition to the more general case of variable returns to scale and apply it to data on secondary education, in which we explicitly take different socio-economic environments into account. We show the importance of this decomposition by applying it to data on Dutch secondary schools and by showing that the influence of the environment on productivity is different for different types of schools with different environments. Another contribution is the implication of these results for schools. Future studies taking into account the environment, could, for example, lead to completely different rankings, such as the three-yearly international PISA (Programme for International Student Assessment) comparisons (OECD) and the four-yearly TIMSS study (Trends in International Mathematics and Science study) (National Centre for Education Statistics) which compare the performance of countries in terms of learning outcomes. This also holds for national rankings of secondary schools, such as the yearly ranking in newspaper 'Trouw' in the Netherlands. Changes in these rankings can have far-reaching consequences for schools, especially the ones with a bad environment, such as higher popularity, both

\footnotetext{
2 See also Lovell (2003).

3 O'Donnell (2012) provides a nice decomposition for mix efficiency, which is similar in spirit to the influence of nondiscretionary inputs. However, the programming models used in the estimation are different.
}

for students choosing the school and for teachers wanting to work for the school.

The remainder of this paper is organized as follows. In the next section, we introduce notation and describe the technology. We also show how distance functions can be used to measure technical efficiency, scale efficiency, technical change and environmental harshness in production environments with nondiscretionary exogenous factors of production. In Section 3 we extend the public sector Malmquist productivity index introduced by Johnson and Ruggiero (2011) and decompose it into technical, efficiency, environmental harshness and scale efficiency change. In Section 4, we apply our model to analyze productivity of Dutch schools using 2002-2007 data. The results indicate that the environment indeed influences the productivity index, as well as the technical, efficiency, scale and environmental change. We see that schools with a moderate classification of environment have the highest productivity numbers. In line with expectations, schools with the worst environment also perform worse and would perform lot better when they would have a different environment. The last section concludes the paper.

\section{Technology representation}

\subsection{Description of the technology}

We assume that each of $n$ production units uses a vector $X^{t}=\left(x_{1}^{t}, \ldots, x_{m}^{t}\right)$ of $m$ discretionary inputs to produce a vector $Y^{t}=\left(y_{1}^{t}, \ldots, y_{s}^{t}\right)$ of $s$ outputs while facing an environment characterized by index $z^{t}$ in time $t(t=T, T+1) .{ }^{4}$ Data for each producer $j$ in time $t$ for $t=T, T+1$ are given by $X_{j}^{t}=\left(x_{1 j}^{t}, \ldots, x_{m j}^{t}\right), \quad Y_{j}^{t}=$ $\left(y_{1 j}^{t}, \ldots, y_{s j}^{t}\right)$ and $z_{j}^{t}$. ${ }^{5}$ The empirical production possibility set defined in time $t$ for $t=T, T+1$ is given by:

$$
\begin{aligned}
\tau_{V}^{t}\left(z^{t}\right)=\left\{\left(Y^{t}, X^{t}, z^{t}\right):\right. & \sum_{i=1}^{n} \lambda_{i} y_{s i}^{t} \geqslant y_{s}^{t}, \quad s=1, \ldots, S ; \\
& \sum_{i=1}^{n} \lambda_{i} x_{m i}^{t} \leqslant x_{m}^{t}, \quad m=1, \ldots, M ; \\
& \sum_{i=1}^{n} \lambda_{n}=1 ; \\
& \lambda_{i}=0 \text { if } z_{i}^{t}>z^{t}, \quad i=1, \ldots, N ; \\
& \left.\lambda_{i} \geqslant 0, \quad i=1, \ldots, N\right\} .
\end{aligned}
$$

The technology described in (1) is the standard nonparametric representation that allow variable returns to scale (VRS) with respect to changes in the scale of operation for the discretionary inputs. In addition, the technology is conditional on the level of the environment. We assume that output is monotonic with respect to the environmental index; a higher value of $z$ implies a more favorable operating environment where the producer should produce at least as much output for any given mix of discretionary inputs.For completeness, we also define the technologies in each time period $t(t=T, T+1)$ under the assumption of constant returns to scale (CRS). These are obtained from (1) by removing the convexity constraint:

\footnotetext{
${ }^{4}$ We adopt the convention of referring to specific time periods with upper case $T$ and $T+1$ and use lower case $t$ as an index value to generically refer to either or both time periods. Likewise, $j$ will be used to index over the set of $n$ producers.

${ }^{5}$ Following our empirical application, we assume only one nondiscretionary input in our exposition. If there are multiple nondiscretionary inputs, the multiple stage model of Ruggiero (1998) can be used to estimate an index of environmental harshness. See Haelermans and Ruggiero (2013) for a discussion.
} 


$$
\begin{aligned}
\tau_{C}^{t}\left(z^{t}\right)=\left\{\left(Y^{t}, X^{t}, z^{t}\right):\right. & \sum_{i=1}^{n} \lambda_{i} y_{s i}^{t} \geqslant y_{s}^{t}, \quad s=1, \ldots, S ; \\
& \sum_{i=1}^{n} \lambda_{i} x_{m i}^{t} \leqslant x_{m}^{t}, \quad m=1, \ldots, M ; \\
& \lambda_{i}=0 \text { if } z_{i}^{t}>z^{t}, \quad i=1, \ldots, N ; \\
& \left.\lambda_{i} \geqslant 0, \quad i=1, \ldots, N\right\} .
\end{aligned}
$$

We illustrate technologies defined by (1) and (2) in Fig. 1, where we assume for simplicity one discretionary input and one discretionary output. Only one data point is shown with observation in times $T\left(A^{T}\right)$ and $T+1\left(A^{T+1}\right)$. We include two vertical axes to reduce clutter. In addition, we assume only two levels of the environmental variable in time $t\left(z_{A}^{t}\right.$ and $\left.z_{B}^{t}\right)$ with $\left(z_{A}^{t}<z_{B}^{t}\right)$ for $t(t=T, T+1)$. Here, $z_{A}^{t}$ and $z_{A}^{t+1}$ are the observed levels of the environmental variable for producer $A$, which faces a harsher environment than some producer $B$ that is observed having the most favorable environment.

There are four VRS technologies illustrated with solid lines depending on the time period and the associated environment: $\tau_{V}^{t}\left(z_{A}^{t}\right)$ and $\tau_{V}^{t}\left(z_{B}^{t}\right)$ for $t=T, T+1$. The frontier associated with $\tau_{V}^{t}\left(z_{A}^{t}\right)$ is a subset of $\tau_{V}^{t}\left(z_{B}^{t}\right)$ implying that producer $A$ cannot achieve the same level of output as producer $B$ because it faces a harsher environment. The assumption with respect to the VRS frontiers is that technical progress exists regardless of the level of environmental harshness. Dashed CRS frontiers $\tau_{C}^{t}\left(z_{A}^{t}\right)$ and $\tau_{C}^{t}\left(z_{B}^{t}\right)$ for $t=T, T+1$ are superimposed on the VRS frontiers to allow us to identify most productive scale size.

\subsection{Measuring technical efficiency}

Given the above technologies, we can project a given production possibility to the boundary of the relevant frontier using distance functions. In this paper, we only use output oriented projections holding inputs fixed and consider the projection for producer $j(j=1, \ldots, n)$. We first consider projections with distance functions that provide measures of technical efficiency:

Definition. $D_{V}^{t}\left(Y_{j}^{t}, X_{j}^{t}, z_{j}^{t}\right)=\left(\max \left\{\theta:\left(\theta Y_{j}^{t}, X_{j}^{t}, z_{j}^{t}\right) \in \tau_{V}^{t}\left(z_{j}^{t}\right)\right\}\right)^{-1} \leqslant 1$ is the output-oriented measure of technical efficiency for $\left(X_{j}^{t}, Y_{j}^{t}, z_{j}^{t}\right) \in \tau_{V}^{t}\left(z_{j}^{t}\right)$ in time $t(t=T, T+1)$.

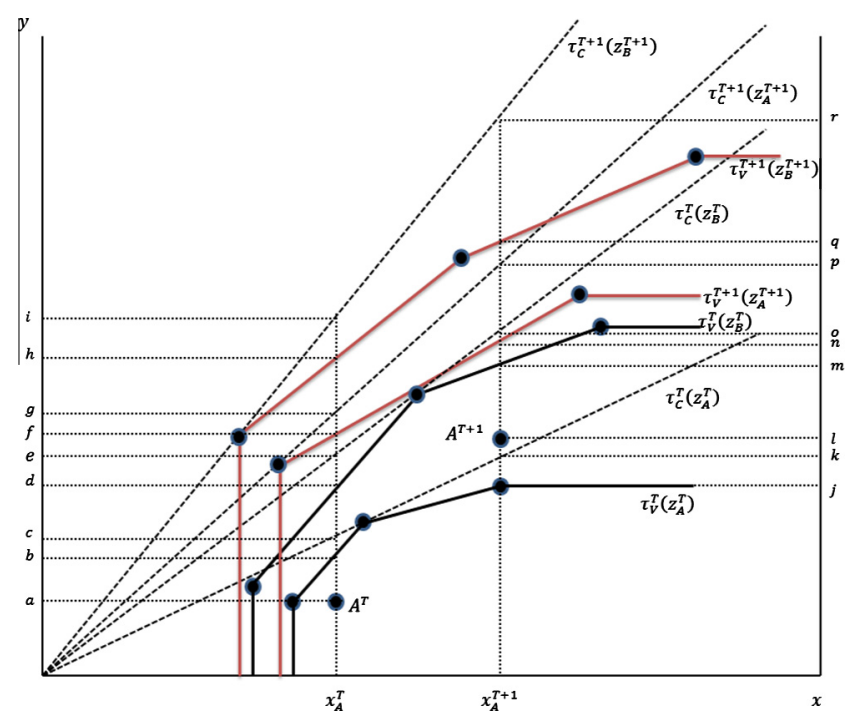

Fig. 1. VRS and CRS technologies across time.
The value of each distance function measuring technical efficiency can be obtained for producer $j$ in time $t(t=T, T+1)$ as the solution to the following linear programming $\operatorname{model}^{6}$ :

$$
\begin{aligned}
& {\left[D_{V}^{t}\left(Y_{j}^{t}, X_{j}^{t}, z_{j}^{t}\right)\right]^{-1}=\operatorname{Max} \theta} \\
& \sum_{i=1}^{n} \lambda_{i} y_{k i}^{t} \geqslant \theta y_{k j}^{t}, \quad k=1, \ldots, s ; \\
& \sum_{i=1}^{n} \lambda_{i} x_{l i}^{t} \leqslant x_{l j}^{t}, \quad l=1, \ldots, m ; \\
& \sum_{i=1}^{n} \lambda_{i}=1 ; \\
& \lambda_{i}=0 \text { if } z_{i}^{t}>z_{j}^{t}, \quad i=1, \ldots, n ; \\
& \lambda_{i} \geqslant 0, \quad i=1, \ldots, n .
\end{aligned}
$$$$
\text { s.t. }
$$

Referring to Fig. 1, the calculation of technical efficiency for production possibility $A$ in time period $T$ is given by $\frac{a}{b}$, which is the observed output divided by the technically efficient output identified by the vertical projection to the frontier $\tau_{V}^{T}\left(z_{A}^{T}\right)$. Likewise, the technical efficiency of $A$ in time period $T+1$ is $\frac{l}{n}$ based on the vertical projection to the frontier of technology $\tau_{V}^{T+1}\left(z_{A}^{T+1}\right)$. These results are consistent with the public sector model of Ruggiero (1996).

\subsection{Measuring scale efficiency}

Banker (1984), Banker et al. (1984) and Färe and Grosskopf (1985) consider projections to both VRS and CRS frontiers to separate pure technical efficiency from scale efficiency. In the previous sections, we considered projections of observations in a given time period to the VRS frontier of the same time period. The result is a measure of technical efficiency, i.e. the ratio of observed to maximum production. We next consider projections with distance functions to the CRS frontiers that provide measures composed of pure technical and scale efficiency:

Definition. $D_{C}^{t}\left(Y_{j}^{t}, X_{j}^{t}, z_{j}^{t}\right)=\left(\max \left\{\theta:\left(\theta Y_{j}^{t}, X_{j}^{t}, z_{j}^{t}\right) \in T_{C}^{t}\left(z_{j}^{t}\right)\right\}\right)^{-1}$ is the output-oriented measure of technical and scale efficiency for $\left(X_{j}^{t}, Y_{j}^{t}, z_{j}^{t}\right) \in T_{C}^{t}\left(z_{j}^{t}\right)$ in time $t(t=T, T+1)$.

The value of the CRS distance functions can be obtained for producer $j$ in time $t(t=T, T+1)$ as the solution to the following linear programming models ${ }^{7}$ :

$$
\begin{aligned}
& \quad\left[D_{C}^{t}\left(Y_{j}^{t}, X_{j}^{t}, z_{j}^{t}\right)\right]^{-1}=\operatorname{Max} \theta \\
& \text { s.t. } \\
& \sum_{i=1}^{n} \lambda_{i} y_{k i}^{t} \geqslant \theta y_{k j}^{t}, \quad k=1, \ldots, s ; \\
& \sum_{i=1}^{n} \lambda_{i} x_{l i}^{t} \leqslant x_{l j}^{t}, \quad l=1, \ldots, m ; \\
& \lambda_{i}=0 \text { if } z_{i}^{t}>z_{j}^{t}, \quad i=1, \ldots, n ; \\
& \lambda_{i} \geqslant 0, \quad i=1, \ldots, n .
\end{aligned}
$$

Models (4) is obtained from (3) with the removal of the convexity constraint.

In Fig. 1, we observe $D_{C}^{T}\left(y_{A}^{T}, x_{A}^{T}, z_{A}^{T}\right)=\frac{a}{b}$ and $D_{C}^{T+1}\left(y_{A}^{T+1}, x_{A}^{T+1}, z_{A}^{T+1}\right)$ $=\frac{l}{o}$. These distances would be measures of technical efficiency if the technology did exhibit constant returns to scale over the relevant range. Under our assumption of VRS, however, the measure

\footnotetext{
${ }^{6}$ Linear programming models (3) are the VRS models introduced in Banker et al. (1984) and extended by Ruggiero (1996b) to be conditional on the environment.

${ }^{7}$ Linear programming models (4) are the CRS models from Charnes et al. (1978) conditional on the environment.
} 
consists of both technical and scale efficiency. As shown, production possibility $A$ in time period $T$ is operating under increasing returns to scale after its technical inefficiency is removed. In time period $T+1, A$ is operating under decreasing returns to scale. Following Färe and Grosskopf (1985) among others, scale efficiency can be defined for producer $j$ in time $t(t=T, T+1)$ using the ratio of distance functions:

Definition. $S E^{t}\left(Y_{j}^{t}, X_{j}^{t}, Z_{j}^{t}\right)=\frac{D_{C}^{t}\left(Y_{j}^{t}, X_{j}^{t}, z_{j}^{t}\right)}{D_{V}^{t}\left(Y_{j}^{t}, X_{j}^{t}, y_{j}^{t}\right)} \leqslant 1$ is the scale efficiency for $\left(X_{j}^{t}, Y_{j}^{t}, z_{j}^{t}\right)$ in time period t.

Again referring to Fig. 1, we observe $S E^{T}\left(y_{A}^{T}, x_{A}^{T}, z_{A}^{T}\right)=\frac{b}{c}$ in time $T$ and $S E^{T+1}\left(y_{A}^{T+1}, x_{A}^{T+1}, z_{A}^{T+1}\right)=\frac{n}{o}$ in time $T+1$. The measures being less than unity indicate that producer $A$ is not operating at the optimal scale size, i.e. on a constant returns to scale facet of the VRS frontier.

\subsection{Measuring environmental harshness}

To this point, we have only considered conditional estimators that properly control for the environment. We now consider gauging the effect the environment has on production; in particular, for the output oriented models, it is important to measure the shortfall in output that results for a given input mix for efficient producers that face a harsher environment. Ruggiero (2000) showed that we can obtain this measure by solving two programming models with and without the conditional on the environmental variable. First, we define VRS and CRS technologies, respectively, unconditioned on the environment in time $t(t=T, T+1)$ :

$$
\begin{aligned}
\hat{\tau}_{V}^{t}=\left\{\left(Y^{t}, X^{t}\right)\right. & : \sum_{i=1}^{n} \lambda_{i} y_{s i}^{t} \geqslant y_{s}^{t}, \quad s=1, \ldots, S ; \\
& \sum_{i=1}^{n} \lambda_{i} x_{m i}^{t} \leqslant x_{m}^{t}, \quad m=1, \ldots, M ; \\
& \sum_{i=1}^{n} \lambda_{i}=1 ; \\
& \left.\lambda_{i} \geqslant 0, \quad i=1, \ldots, N\right\} .
\end{aligned}
$$

and

$$
\begin{aligned}
\hat{\tau}_{V}^{t}=\left\{\left(Y^{t}, X^{t}\right)\right. & : \sum_{i=1}^{n} \lambda_{i} y_{s i}^{t} \geqslant y_{s}^{t}, \quad s=1, \ldots, S ; \\
& \sum_{i=1}^{n} \lambda_{i} x_{m i}^{t} \leqslant x_{m}^{t}, \quad m=1, \ldots, M ; \\
& \left.\lambda_{i} \geqslant 0, \quad i=1, \ldots, N\right\} .
\end{aligned}
$$

Importantly, these technologies do not provide feasible projections for producers without the most favorable environment. Instead, they provide projections that could have been possible if the producer had the most favorable environment. For ease of discussion, we will refer to this as potential output (under most favorable conditions).

Given these technologies, we now consider the following distance functions to evaluate what could have been possible if the unit had the most favorable environment:

Definition. $D_{V}^{t}\left(Y_{j}^{t}, X_{j}^{t}\right)=\left(\max \left\{\theta:\left(\theta Y_{j}^{t}, X_{j}^{t}\right) \in \hat{\tau}_{V}^{t}\right\}\right)^{-1}$ is the outputoriented distance function projecting $\left(X_{j}^{t}, Y_{j}^{t}, z_{j}^{t}\right)$ to the boundary of $\hat{\tau}_{V}^{t}$ in time $t(t=T, T+1)$. Likewise, $D_{C}^{t}\left(Y_{j}^{t}, X_{j}^{t}\right)=\left(\max \left\{\theta:\left(\theta Y_{j}^{t}, X_{j}^{t}\right)\right.\right.$ $\left.\left.\in \hat{\tau}_{C}^{t}\right\}\right)^{-1}$ projects $\left(X_{j}^{t}, Y_{j}^{t}, z_{j}^{t}\right)$ to the boundary of $\hat{\tau}_{C}^{t}$ in time $t(t=T, T+1)$.

The values of these distance functions are obtained for producer $j$ in time $t(t=T, T+1)$ as the solution to the following linear programming models:

$$
\left[D_{V}^{t}\left(Y_{j}^{t}, X_{j}^{t}\right)\right]^{-1}=\operatorname{Max} \theta
$$

s.t.

$$
\begin{aligned}
& \sum_{i=1}^{n} \lambda_{i} y_{k i}^{k} \geqslant \theta y_{k j}^{t}, \quad k=1, \ldots, s ; \\
& \sum_{i=1}^{n} \lambda_{i} x_{l i}^{t} \leqslant x_{l j}^{t}, \quad l=1, \ldots, m ; \\
& \sum_{i=1}^{n} \lambda_{i}=1 ; \\
& \lambda_{i} \geqslant 0, \quad i=1, \ldots, n .
\end{aligned}
$$

and

$$
\left[D_{C}^{t}\left(Y_{j}^{t}, X_{j}^{t}\right)\right]^{-1}=\operatorname{Max} \theta
$$

s.t.

$$
\begin{aligned}
& \sum_{i=1}^{n} \lambda_{i} y_{k i}^{k} \geqslant \theta y_{k j}^{t}, k=1, \ldots, s ; \\
& \sum_{i=1}^{n} \lambda_{i} x_{l i}^{t} \leqslant x_{l j}^{t}, l=1, \ldots, m ; \\
& \lambda_{i} \geqslant 0, \quad i=1, \ldots, n .
\end{aligned}
$$

These models are similar to the technical efficiency measures defined above with the only difference being the exclusion of the constraint on the nondiscretionary factor. Referring to Fig. 1, we observe the value of these distance functions for $A$ in time period $T$ as $D_{V}^{T}\left(y_{A}^{T}, x_{A}^{T}\right)=\frac{a}{d}$ and $D_{C}^{T}\left(y_{A}^{T}, x_{A}^{T}\right)=\frac{a}{e} .{ }^{8}$ For $A$ in time period $T+1$ we find $D_{V}^{T+1}\left(y_{A}^{T+1}, x_{A}^{T+1}\right)=\frac{l}{q}$ and $D_{C}^{T+1}\left(y_{A}^{T+1}, x_{A}^{T+1}\right)=\frac{l}{r}$.

Following Ruggiero (2000) and Johnson and Ruggiero (2011), we can now measure an index of environmental harshness as:

Definition. $E_{V}^{t}\left(Y_{j}^{t}, X_{j}^{t}, z_{j}^{t}\right)=\frac{D_{V}^{t}\left(Y_{j}^{t}, X_{j}^{t}\right)}{D_{V}^{t}\left(Y_{j}^{t}, X_{j}^{t},,_{j}^{t}\right)}$ and $E_{C}^{t}\left(Y_{j}^{t}, X_{j}^{t}, z_{j}^{t}\right)=\frac{D_{C}^{t}\left(Y_{j}^{t}, X_{j}^{t}\right)}{D_{C}^{t}\left(Y_{j}^{t}, X_{j}^{t},,_{j}^{t}\right)}$ are measures of environmental harshness for $\left(X_{j}^{t}, Y_{j}^{t}, z_{j}^{t}\right)$ in time period $t(t=T, T+1)$ under the assumption of variable and constant returns to scale, respectively.

Returning to Fig. 1, we observe $E_{V}^{T}\left(y_{A}^{T}, x_{A}^{T}, z_{A}^{T}\right)=\frac{b}{d}$ and $E_{C}^{T}\left(y_{A}^{T}, x_{A}^{T}, z_{A}^{T}\right)=\frac{c}{e}$ in time $T$ and $E_{V}^{T+1}\left(y_{A}^{T+1}, x_{A}^{T+1}, z_{A}^{T+1}\right)=\frac{n}{q}$ and $E_{C}^{T+1}\left(y_{A}^{T+1}, x_{A}^{T+1}, z_{A}^{T+1}\right)=\frac{p}{r}$ in time $T+1$.

In addition, give the distance functions defined relative to the most favorable environment we can analyze the scale efficiency of the frontiers that are not conditioned on the exogenous nondiscretionary factor. We now define scale efficiency for the most favorable environments similar to the definition above:

Definition. $S E^{t}\left(Y_{j}^{t}, X_{j}^{t}\right)=\frac{D_{C}^{t}\left(Y_{j}^{t}, X_{j}^{t}\right)}{D_{V}^{t}\left(Y_{j}^{t}, X_{j}^{t}\right)}$ is the scale efficiency measure for observed production units $\left(X_{j}^{t}, Y_{j}^{t}, z_{j}^{t}\right)$ in time period $t(t=T, T+1)$ assuming that the unit faced the most favorable environment.

For producer $A$ in Fig. $1, S E^{T}\left(y_{A}^{T}, x_{A}^{T}\right)=\frac{d}{e}$ and $S E^{T+1}\left(y_{A}^{T+1}, x_{A}^{T+1}\right)=\frac{q}{r}$. As shown, most productive scale size depends on the environment; in time period $T$ most productive scale size for units facing the most favorable environment happens at a higher input level than for units with the harsher environment. In time period $T+1$ the most productive scale size occurs at much lower input levels than it does for the harsher environment. As a result, $A$ is closer to most productive scale size given its environment in both time periods.

\footnotetext{
${ }^{8}$ Here, to avoid making the graph more cluttered, we are assume $\hat{\tau}_{V}^{t}=T_{V}^{t}\left(z_{B}^{t}\right), \hat{\tau}_{C}^{t}=T_{C}^{t}\left(z_{B}^{t}\right), \hat{\tau}_{V}^{t+1}=T_{V}^{t+1}\left(z_{B}^{t+1}\right)$ and $\hat{\tau}_{C}^{t+1}=T_{C}^{t+1}\left(z_{B}^{t+1}\right)$. In practice, this assumption will hold only for a sufficiently large sample size. Regardless, we use the distance functions without the conditions to obtain these measures.
} 


\subsection{Cross-period measures and technical change}

In the previous subsections, we have only considered projections of observed data points to frontier technologies defined in the same period. Another useful measure is to compare projections of a point in given time period to frontier technologies in a different time period. We define these projections with the following distance functions:

$$
\begin{aligned}
D_{V}^{t}\left(Y_{j}^{u}, X_{j}^{u}, z_{j}^{u}\right) & =\left(\max \left\{\theta:\left(\theta Y_{j}^{u}, X_{j}^{u}, z_{j}^{u}\right) \in \tau_{V}^{t}\left(z_{j}^{u}\right)\right\}\right)^{-1} \text { for } t, u \\
& =T, T+1 \text { and } t \neq u ; \\
D_{C}^{t}\left(Y_{j}^{u}, X_{j}^{u}, z_{j}^{u}\right) & =\left(\max \left\{\theta:\left(\theta Y_{j}^{u}, X_{j}^{u}, z_{j}^{u}\right) \in \tau_{C}^{t}\left(z_{j}^{u}\right)\right\}\right)^{-1} \text { for } t, u \\
& =T, T+1 \text { and } t \neq u ; \\
D_{V}^{t}\left(Y_{j}^{u}, X_{j}^{u}\right)= & \left(\max \left\{\theta:\left(\theta Y_{j}^{u}, X_{j}^{u}\right) \in\left(\hat{\tau}_{V}^{t}\right\}\right)^{-1} \text { for } t, u\right. \\
= & T, T+1 \text { and } t \neq u ; \quad \text { and } D_{C}^{t}\left(Y_{j}^{u}, X_{j}^{u}\right) \\
= & \left(\max \left\{\theta:\left(\theta Y_{j}^{u}, X_{j}^{u}\right) \in\left(\hat{\tau}_{C}^{t}\right)\right\}\right)^{-1} \text { for } t, u \\
= & T, T+1 \text { and } t \neq u .
\end{aligned}
$$

These distance functions replicate the ones defined in previous subsections. As a result, for a given point $j$ in time $t(t=T, T+1)$ we obtain four additional projections beyond the ones defined above. ${ }^{9}$

These cross period distance functions allow us to measure technical change, i.e. the shift in frontier technologies across time. Färe, Grosskopf, Lindgren, and Roos (1992) showed that technical change could be measured as the ratio of two distance functions. Conditioning on the environment, we define technical change between frontiers as:

Definition. $T C_{V}\left(Y_{j}^{u}, X_{j}^{u}, z_{j}^{u}\right)=\frac{D_{V}^{T}\left(Y_{j}^{u}, X_{j}^{u}, z_{j}^{u}\right)}{D_{V}^{T+1}\left(Y_{j}^{u}, X_{j}^{u}, z_{j}^{u}\right)}$ measures technical change for producer $j$ observed in time $u(u=T, T+1)$ using VRS frontier technologies conditioned on the environment. Likewise, $T C_{C}\left(Y_{j}^{u}, X_{j}^{u}, z_{j}^{u}\right)=\frac{D_{C}^{T}\left(Y_{j}^{u}, X_{j}^{u}, z_{j}^{u}\right)}{D_{C}^{T+1}\left(Y_{j}^{u}, X_{j}^{u}, z_{j}^{u}\right)}$ measures technical change for producer $j$ observed in time $u(u=T, T+1)$ using CRS frontier technologies conditioned on the environment.

For producer $A$ in Fig. $1, T C_{V}\left(y_{A}^{T}, x_{A}^{T}, z_{A}^{T}\right)=\frac{f}{b}>1$ and $T C_{V}\left(y_{A}^{T+1}, x_{A}^{T+1}, z_{A}^{T+1}\right)=\frac{n}{j}>1$. Here, we are measuring technical change between the VRS frontier technologies conditional on the environment. We also observe $T C_{C}\left(y_{A}^{T}, x_{A}^{T}, z_{A}^{T}\right)=\frac{g}{c}>1$ and $T C_{C}\left(y_{A}^{T+1}, x_{A}^{T+1}, z_{A}^{T+1}\right)=\frac{p}{k}>1$ for the technical change between CRS frontier technologies conditional on the environment. For producer $A$ we observe technical progress regardless of whether we use CRS or VRS technologies or whether we anchor the measure using data observed in $T$ or $T+1$.

Finally, we can define technical change for the units facing the most favorable environment:

Definition. $T C_{V}\left(Y_{j}^{u}, X_{j}^{u}\right)=\frac{D_{V}^{T}\left(Y_{j}^{u}, X_{j}^{u}\right)}{D_{V}^{T+1}\left(Y_{j}^{u}, X_{j}^{u}\right)}$ measures technical change for producer $j$ observed in time $u(u=T, T+1)$ using VRS frontier technologies assuming the most favorable environment. Similarly, $T C_{C}\left(Y_{j}^{u}, X_{j}^{u}\right)=\frac{D_{C}^{T}\left(Y_{j}^{u}, X_{j}^{u}\right)}{D_{C}^{T+1}\left(Y_{j}^{u}, X_{j}^{u}\right)}$ measures technical change for producer $j$ observed in time $u(u=T, T+1)$ using CRS frontier technologies assuming the most favorable environment.

\footnotetext{
${ }^{9}$ It is well understood in the literature that feasibility issues arise when projecting a point in a given time period to a VRS frontier technology in a different period. We follow convention in the empirical section and report results only for those solutions that are feasible. For space consideration, we have omitted the linear programs associated with the cross period distance functions.
}

For technical change assuming the producer $A$ has the most favorable environment in Fig. $1, T C_{V}\left(y_{A}^{T}, x_{A}^{T}\right)=\frac{h}{d}>1$ and $T C_{V}\left(y_{A}^{T+1}, x_{A}^{T+1}\right)=\frac{q}{m}>1$. Likewise, we observe $T C_{C}\left(y_{A}^{T}, x_{A}^{T}\right)=\frac{i}{e}>1$ and $T C_{C}\left(y_{A}^{T+1}, x_{A}^{T+1}\right)=\frac{r}{0}>1$ for the technical change measures between CRS frontier technologies assuming the most favorable environments.

\section{Public sector Malmquist productivity measure}

Färe et al. (1992) extended Caves et al. (1982) to show how to measure an input-based Malmquist productivity index using nonparametric distance functions. Färe et al. (1992) also provided a decomposition to show that productivity could be decomposed into efficiency change and technical change. Färe et al. (1994) provided an output-based Malmquist index and showed how scale efficiency change can be incorporated. In a response to Färe et al. (1994) and Ray and Desli (1997) provided an alternative decomposition of the Malmquist productivity with three parts: efficiency change, technical change and scale efficiency change. These models are based on production processes without nondiscretionary environmental factors of production. Ouellette and Vierstraete (2010) and Johnson and Ruggiero (2011) provided alternative decompositions when fixed factors of production are present. Here, we extend Johnson and Ruggiero (2011) to further decompose their Environmental Malmquist Productivity Index (EMPI) to include scale effects. ${ }^{10}$

The EMPI can be estimated for producer $j$ as:

$$
\begin{gathered}
\operatorname{EMPI}\left(Y_{j}^{T+1}, X_{j}^{T+1}, z_{j}^{T+1}, Y_{j}^{T}, X_{j}^{T}, z_{j}^{T}\right) \\
=\left[\frac{D_{C}^{T}\left(Y_{j}^{T+1}, X_{j}^{T+1}, z_{j}^{T+1}\right)}{D_{C}^{T}\left(Y_{j}^{T}, X_{j}^{T}, z_{j}^{T}\right)} \frac{D_{C}^{T+1}\left(Y_{j}^{T+1}, X_{j}^{T+1}, z_{j}^{T+1}\right)}{D_{C}^{T+1}\left(Y_{j}^{T}, X_{j}^{T}, z_{j}^{T}\right)}\right]^{\frac{1}{2}} .
\end{gathered}
$$

This formulation is similar to the one provided in Färe et al. (1994) with the environmental variable included. ${ }^{11}$ The evaluation of productivity is the geometric mean to avoid arbitrarily choosing a particular year as the benchmark technology.

Following Ray and Desli (1997) we can decompose (9) as follows:

$$
\begin{aligned}
& \operatorname{EMPI}\left(Y_{j}^{T+1}, X_{j}^{T+1}, z_{j}^{T+1}, Y_{j}^{T}, X_{j}^{T}, z_{j}^{T}\right)= \\
& \frac{D_{V}^{T+1}\left(Y_{j}^{T+1}, X_{j}^{T+1}, z_{j}^{T+1}\right)}{D_{V}^{T}\left(Y_{j}^{T}, X_{j}^{T}, z_{j}^{T}\right)} x \\
& {\left[\frac{D_{V}^{T}\left(Y_{j}^{T}, X_{j}^{T}, z_{j}^{T}\right)}{D_{V}^{T+1}\left(Y_{j}^{T}, X_{j}^{T}, z_{j}^{T}\right)} \frac{D_{V}^{T}\left(Y_{j}^{T+1}, X_{j}^{T+1}, z_{j}^{T+1}\right)}{D_{V}^{T+1}\left(Y_{j}^{T+1}, X_{j}^{T+1}, z_{j}^{T+1}\right)}\right]^{\frac{1}{2}} x} \\
& {\left[\frac{S E^{T}\left(Y_{j}^{T+1}, X_{j}^{T+1}, z_{j}^{T+1}\right)}{S E^{T}\left(Y_{j}^{T}, X_{j}^{T}, z_{j}^{T}\right)} \frac{S E^{T+1}\left(Y_{j}^{T+1}, X_{j}^{T+1}, z_{j}^{T+1}\right)}{S E^{T+1}\left(Y_{j}^{T}, X_{j}^{T}, z_{j}^{T}\right)}\right]^{\frac{1}{2}} .}
\end{aligned}
$$

Here, the productivity index consists of efficiency change, technical change and scale efficiency change. We note that the technical

\footnotetext{
10 O'Donnell (2011) provides a useful discussion of the limitations of the Malmquist productivity measure and presents alternative measures. Decompositions developed in this paper could be applied to the other productivity measures.

11 Essid et al. (2014) also decompose the Malmquist index to allow scale changes in the presence of nondiscretionary inputs but rely on the Banker and Morey (1986a) model for estimation. See Ruggiero (1996b) for conceptual problems with this approach.
} 
change and scale efficiency change components, like the EMPI, are expressed as geometric means to avoid arbitrarily choosing the time period for either the projection point (technical change) or the reference technology (scale efficiency change).

Using the definition for environmental harshness, we can further decompose the technical change component ${ }^{12}$ :

$$
\begin{aligned}
\text { Technical Change }= & {\left[\frac{D_{V}^{T}\left(Y_{j}^{T}, X_{j}^{T}, z_{j}^{T}\right)}{D_{V}^{T+1}\left(Y_{j}^{T}, X_{j}^{T}, z_{j}^{T}\right)} \frac{D_{V}^{T}\left(Y_{j}^{T+1}, X_{j}^{T+1}, z_{j}^{T+1}\right)}{D_{V}^{T+1}\left(Y_{j}^{T+1}, X_{j}^{T+1}, z_{j}^{T+1}\right)}\right]^{\frac{1}{2}} } \\
= & {\left[\frac{D_{V}^{T}\left(Y_{j}^{T}, X_{j}^{T}\right)}{D_{V}^{T+1}\left(Y_{j}^{T}, X_{j}^{T}\right)} \frac{D_{V}^{T}\left(Y_{j}^{T+1}, X_{j}^{T+1}\right)}{D_{V}^{T+1}\left(Y_{j}^{T+1}, X_{j}^{T+1}\right)}\right]^{\frac{1}{2}} x } \\
& {\left[\frac{E_{V}^{T+1}\left(Y_{j}^{T}, X_{j}^{T}, z_{j}^{T}\right)}{E_{V}^{T}\left(Y_{j}^{T}, X_{j}^{T}, z_{j}^{T}\right)} \frac{E_{V}^{T+1}\left(Y_{j}^{T+1}, X_{j}^{T+1}, z_{j}^{T+1}\right)}{E_{V}^{T}\left(Y_{j}^{T+1}, X_{j}^{T+1}, z_{j}^{T+1}\right)}\right]^{\frac{1}{2}} }
\end{aligned}
$$

Here, the technical change is decomposed into the technical change associated with the most favorable environment VRS frontier technology and the change in environmental harshness. Hence, we are able to decompose the EMPI into efficiency change, technical change using the most favorable environment (MFE), the change in environmental harshness and scale efficiency change. This decomposition is similar to the one provided in Johnson and Ruggiero (2011); however, in this paper the change in environmental harshness is defined with the VRS and not the CRS technology and we provide the additional scale efficiency component as in Ray and Desli (1997).

\section{Efficiency and productivity in Dutch schools}

In this section we describe the data and apply our models to analyze the change in efficiency, technical efficiency, environmental harshness and scale efficiency.

\subsection{Data}

Dutch secondary education offers four different levels of education, which are concluded with a national examination in the last year. Students enter a level of education based on a recommendation given in elementary school. Secondary education takes 4,5 or 6 years to complete, depending on the level of education. Most schools offer a combination of these four levels of education, but some only offer one of these levels and are considered specialized schools. Secondary schools in the Netherlands receive a lump sum payment from the government every year. Within the existing legal framework, the allocation of this budget among the several resources is the decision of the school. A more extensive discussion of Dutch secondary education can be found in Haelermans, De Witte, and Blank (2012) and (Haelermans \& Ruggiero, 2013).

We use a representative dataset of 448 public Dutch secondary schools ${ }^{13}$ covering the school years 2002/2003-2007/2008. For convenience, we refer to school year $2002 / 2003$ as 2002, to school year 2003/2004 as 2003 and so on. The data are obtained from several existing administrative data sets from the Ministry of Education, the Education Inspectorate and Statistics Netherlands.

\subsubsection{Production}

Educational production is often defined as the development of knowledge and skills during school. We use three measures for

\footnotetext{
12 Other decompositions are of course possible.

13 All schools in the Netherlands are public in the sense that they are publicly financed and evaluated by public institutions.
}

educational production ( 3 outputs): the average student national examination grades per school, the average student achievement each year during secondary education and the total number of students (enrollment). Several other studies use the number of students and the subsequent student performance (e.g. Blank, Koot, \& van Hulst, 2007a, 2007b; Haelermans, 2012; Haelermans \& Blank, 2012; Haelermans et al., 2012), whereas other studies only use the number of students of certain years or only use student performance or change in student performance as an output measure (e.g. Afonso \& St. Aubyn, 2006; Blank et al., 2007b; Conroy \& Arguea, 2008; Dijkgraaf, van der Geest, \& de Jong, 2008; Grosskopf, Hayes, \& Taylor, 2009; Millimet \& Collier, 2008). This studies belongs to the first group, that includes both. We believe that our outputs reflect indicators that are often referred to as 'quality indicators', for example, student performance, student teacher ratio, and the number of students (OECD, 2010). Including these indicators may lead to a better representation of reality in the efficiency study, and might lead to a larger spread among the efficiency scores, as more information on the differences between educational institutes is taken into account.

A graduating student undertakes the national exams at the end of secondary education for the subjects the student is registered. The exams are graded in a double blind way. The average grade per school is based on the average of all national examination grades for all students in all subjects. Note that the level of analysis is the school and not the subject or the student. Furthermore, we include the total number of students and the average aggregated corrected achievement (a composite number of the Education Inspectorate), as a proxy of the quality of the educational process. This number compares the educational track of a student in a given year with the educational track predicted for a student at the end of primary education. An aggregated corrected achievement of 1 denotes that all students are exactly in the year and level of education they are predicted to be according to primary education test results. A value below 1 means that the student is in a lower educational track or a lower year than predicted, a value above 1 means that the student is in a higher track than predicted. Student numbers are also an output as they mainly determine the amount of governmental funding of the school.

Table 1 shows the summary statistics of educational production for all years. We see that the average national examination grade roughly decreases over the years and amounts to 6.4 on a 10 point scale in 2007. Note that a 5.5 is sufficient to pass the subject, although lower than 4 and higher than 9 are very uncommon. Despite the larger variation, the standard error is relatively low. Student achievement has increased between 2002 and 2007 and has an average of 0.832 in 2007 . The total number of students has encountered a large increase and grew from 1656 in 2002 to 1741 in 2007.

\subsubsection{Resources}

School resources are summarized along four relatively homogeneous categories (4 inputs): (1) management personnel, (2) teaching personnel, (3) supporting personnel and (4) material costs. These categories add up to the yearly total expenses of the school, which is usually not very different from the yearly lump sum budget the school received from the government. 'Capital' in the sense of housing infrastructure is not accounted for due to data constraints. Many other studies use costs as input, which can be costs of personnel or materials (see Blank et al., 2007a, 2007b; Grosskopf, Hayes, Taylor, \& Weber, 1997; Ouellette \& Vierstraete, 2005), costs per student (e.g. Chakraborty, Biswas, \& Lewis, 2000; Hoxby, 2004; Ruggiero, 2007), or total costs of a school (Izadi, Johnes, Oskrochi, \& Crouchley, 2002; Kempkes \& Pohl, 2008; Smet \& Nonneman, 1998). As is discussed below, our study belongs to the first group of studies. Costs and personnel and material repre- 
Table 1

Descriptive statistics $(N=448)$.

\begin{tabular}{|c|c|c|c|c|c|c|}
\hline & \multicolumn{2}{|c|}{ Year 2002} & \multicolumn{2}{|c|}{ Year 2003} & \multicolumn{2}{|c|}{ Year 2004} \\
\hline & Mean & Standard deviation & Mean & Standard deviation & Mean & Standard deviation \\
\hline Student numbers & 1656.25 & 951.10 & 1682.99 & 960.83 & 1709.38 & 978.77 \\
\hline National examination grade & 6.45 & 0.22 & 6.46 & 0.23 & 6.41 & 0.22 \\
\hline Student achievement (\%) & 0.80 & 0.07 & 0.82 & 0.06 & 0.83 & 0.06 \\
\hline Management personnel (FTE) & 7.80 & 5.61 & 8.02 & 6.02 & 7.85 & 5.88 \\
\hline Teachers (FTE) & 113.98 & 70.73 & 115.92 & 70.78 & 116.39 & 69.93 \\
\hline Support personnel (FTE) & 26.45 & 17.57 & 28.07 & 18.54 & 28.57 & 18.72 \\
\hline Material expenses (1000s of Euros) & 1584.21 & 1086.73 & 1622.98 & 1095.03 & 1694.71 & 1125.03 \\
\hline \multirow[t]{3}{*}{ Economically advantaged students (\%) } & 97.52 & 2.99 & 97.53 & 2.96 & 97.55 & 2.96 \\
\hline & \multicolumn{2}{|c|}{ Year 2005} & \multicolumn{2}{|c|}{ Year 2006} & \multicolumn{2}{|c|}{ Year 2007} \\
\hline & Mean & Standard Deviation & Mean & Standard Deviation & Mean & Standard Deviation \\
\hline Student numbers & 1718.19 & 977.16 & 1733.71 & 989.69 & 1741.43 & 993.27 \\
\hline National examination grade & 6.38 & 0.22 & 6.36 & 0.21 & 6.38 & 0.22 \\
\hline Student achievement (\%) & 0.82 & 0.06 & 0.82 & 0.06 & 0.83 & 0.06 \\
\hline Management personnel (FTE) & 7.80 & 5.91 & 7.76 & 5.92 & 8.71 & 6.60 \\
\hline Teachers (FTE) & 117.59 & 70.68 & 119.45 & 71.31 & 130.90 & 80.46 \\
\hline Support personnel (FTE) & 29.02 & 18.99 & 29.64 & 19.56 & 23.34 & 15.49 \\
\hline Material expenses (1000s of Euros) & 1927.28 & 1274.92 & 2155.43 & 1526.20 & 2248.82 & 1606.14 \\
\hline Economically advantaged students (\%) & 97.59 & 2.96 & 97.57 & 2.98 & 97.37 & 3.03 \\
\hline All prices in Euros & & & & & & \\
\hline
\end{tabular}

sent a schools' input well, as costs, or total expenses, (or in the Dutch case: the total lump sum budget) represents the financial constraints under which a school operates. In combination with the number of personnel and materials, we believe that this represents the resources to educate students very well.

For the human resources (the first three groups), data are available on full time equivalents (FTE) and costs. Table 1 shows that the total average number of FTE per school equals 163 in 2007 (compared with 148 in 2002), consisting for $80 \%$ out of teachers, $14 \%$ of supporting personnel and the remaining $6 \%$ of managing personnel. The total costs of a school are about 12 million euro in 2007. The majority of the costs are spent on teaching personnel, followed by materials, managing personnel and, finally, supporting personnel. Table 1 also shows that material expenses almost doubled between 2002 and 2007, to 2248 thousand Euros. A similar trend is visible for total expenses, which indicates that the ratio of expenditures on the four resources has not changed that much.

\subsubsection{Exogenous variable}

Some influences are exogenous to the school and create heterogeneity across schools. In this paper we include the share of advantaged students as exogenous variable. Disadvantageous students are students from a disadvantaged neighborhood as indicated by the ministry. Previous research has shown the importance of including this exogenous variable (Becker \& Luthar, 2002; Gaziel, 1997). The share of advantaged students is on average about $95.5 \%$, but we see a small increase in average percentage of advantaged students between 2002 and 2007. Despite the average of $95.5 \%$, this number varies between schools from 80 to $100 \%$. The total share of disadvantaged students in secondary education the Netherlands is rather small.

\subsection{Results}

The main results of our analysis are presented in Table 2. Table 2 shows the number of schools, the Environmental Malmquist Productivity Index (EMPI), the efficiency change, the technical change, the technical change using the most favorable environment (MFE), the change in environmental harshness and the scale efficiency change. Due to infeasibility of the cross-period measures we do not obtain results for all 448 schools. Table 2 presents separate results for (1) all schools, (2) schools with the most favorable environment (share of advantaged students is $100 \%$ ), (3) schools with a high favorable environment, (4) school with a moderate favorable environment, and (5), schools with a low favorable environment. These results are presented for the change between one year and the next, starting with the change from 2002 to 2003 and ending with the change from 2006 to 2007.

We note that productivity (EMPI) increased from 2002 to 2003, 2005 to 2006 and from 2006 to 2007. The group of schools with a moderate favorable environment shows a similar development, but the other groups show different trends. Schools with the least favorable have decreasing productivity for all years except the last while the schools with the most and highly favorable environment have fluctuating results, though very similar to each other. Table 2 shows that technical change is the main reason for this EMPI change. With respect to scale efficiency, we improvements toward most productivity scale size for all years except 2004 .

Focusing on the results from 2006 to 2007, we see that on average there is a $6.9 \%$ increase in productivity (EMPI), which ranges from $12 \%$ in the moderate group to only $0.5 \%$ for the schools with the most favorable environment. For all groups, efficiency decreased on average from 2006 to 2007; however, the average technical change results reveal technical progress for all groups, ranging from $3 \%$ (highly favorable) to $11.8 \%$ (moderate). The observed technical progress is further decomposed to reveal that all groups saw an improvement in the environmental harshness. From 2006 to 2007 there was an increase not only in the best-practice frontier but also a decrease in the effect that the environment had on production. Interestingly, schools with at least the highly favorable environment moved further away from most productive scale size while schools with low and moderate environment realized an improvement in scale efficiency.

We also observe interesting patterns across time. On average, increases (decreases) in productivity are correlated with a decreasing (increasing) effect of the environment on production. For example, from 2002 to 2003 , we observe a $2.9 \%$ increase in productivity on average for all schools while the change in environmental harshness was $2.7 \%$. This pattern is observed for all years and in general, for each classification. The results indicate that productivity improvements are caused less by changes in technical or scale efficiency but rather by technical change due 
Table 2

Average productivity results.

\begin{tabular}{|c|c|c|c|c|c|}
\hline & \multirow[t]{2}{*}{ All schools } & \multicolumn{4}{|c|}{ Classification of environment } \\
\hline & & Most favorable & High & Moderate & Low \\
\hline \multicolumn{6}{|l|}{$2002-2003$} \\
\hline Number of schools & 416 & 47 & 72 & 179 & 118 \\
\hline EMPI & 1.029 & 0.999 & 0.987 & 1.080 & 0.990 \\
\hline Efficiency change & 1.003 & 0.997 & 1.002 & 1.007 & 1.001 \\
\hline Technical change & 1.025 & 1.001 & 0.988 & 1.060 & 1.003 \\
\hline Technical change MFE & 0.999 & 1.001 & 1.000 & 0.996 & 1.001 \\
\hline Change in env. harshness & 1.027 & 1.000 & 0.988 & 1.065 & 1.002 \\
\hline Scale efficiency change & 1.001 & 1.001 & 0.988 & 1.013 & 0.985 \\
\hline \multicolumn{6}{|l|}{$2003-2004$} \\
\hline Number of schools & 310 & 47 & 69 & 106 & 88 \\
\hline EMPI & 0.976 & 1.007 & 0.995 & 0.924 & 1.007 \\
\hline Efficiency change & 0.999 & 1.000 & 0.998 & 0.998 & 0.997 \\
\hline Technical change & 0.976 & 0.998 & 0.934 & 0.934 & 0.999 \\
\hline Technical change MFE & 1.001 & 0.998 & 1.006 & 1.006 & 0.999 \\
\hline Change in env. harshness & 0.976 & 1.000 & 0.929 & 0.929 & 1.000 \\
\hline Scale efficiency change & 1.001 & 1.010 & 0.991 & 0.991 & 1.010 \\
\hline \multicolumn{6}{|l|}{$2004-2005$} \\
\hline Number of schools & 299 & 48 & 67 & 100 & 84 \\
\hline EMPI & 0.962 & 0.994 & 0.970 & 0.922 & 0.986 \\
\hline Efficiency change & 1.003 & 1.007 & 0.998 & 1.004 & 1.004 \\
\hline Technical change & 0.971 & 0.989 & 0.988 & 0.936 & 0.988 \\
\hline Technical change MFE & 0.992 & 0.989 & 0.991 & 0.997 & 0.989 \\
\hline Change in env. harshness & 0.978 & 1.000 & 0.996 & 0.938 & 0.999 \\
\hline Scale efficiency change & 0.988 & 0.998 & 0.985 & 0.980 & 0.994 \\
\hline \multicolumn{6}{|l|}{$2005-2006$} \\
\hline Number of schools & 326 & 49 & 66 & 119 & 92 \\
\hline EMPI & 1.028 & 0.982 & 0.981 & 1.100 & 0.993 \\
\hline Efficiency change & 0.999 & 0.994 & 1.002 & 0.998 & 1.002 \\
\hline Technical change & 1.021 & 0.999 & 0.970 & 1.077 & 0.996 \\
\hline Technical change MFE & 0.998 & 0.999 & 0.995 & 0.999 & 0.996 \\
\hline Change in env. harshness & 1.023 & 1.000 & 0.974 & 1.078 & 1.000 \\
\hline Scale efficiency change & 1.008 & 0.988 & 1.012 & 1.024 & 0.996 \\
\hline \multicolumn{6}{|l|}{$2006-2007$} \\
\hline Number of schools & 309 & 46 & 60 & 115 & 88 \\
\hline EMPI & 1.069 & 1.005 & 1.007 & 1.118 & 1.080 \\
\hline Efficiency change & 0.990 & 0.990 & 0.989 & 0.987 & 0.994 \\
\hline Technical change & 1.069 & 1.031 & 1.030 & 1.114 & 1.055 \\
\hline Technical change MFE & 1.031 & 1.028 & 1.019 & 1.025 & 1.047 \\
\hline Change in env. harshness & 1.036 & 1.003 & 1.009 & 1.086 & 1.007 \\
\hline Scale efficiency change & 1.007 & 0.984 & 0.989 & 1.013 & 1.025 \\
\hline
\end{tabular}

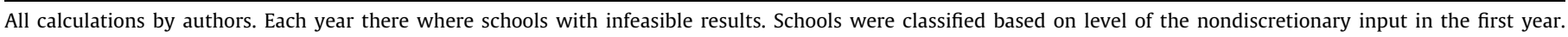
Between 46 and 49 schools had the highest possible level; the last three columns report results for the remaining schools.

to changes in the effect of the environment. Further, the schools with a moderate environment are able to realize the largest gains in productivity from 2002 to 2003 and from 2005. For the schools facing the low environment, we observe real technical progress in 2006 to 2007 due to improvements in scale efficiency and technical progress.

In Table 3, we present illustrative results for a school for each environmental harshness classification: a school in Amsterdam (a large share of disadvantaged students), a school in the province of Noord-Holland (moderate share), a school in the province Zeeland (low share) and a school in the province Overijssel (no disadvantaged students.) Table 3 shows that there are very different results for these four schools. All four are schools with an average size in student population, offering all four types of education. Differences can be seen in the other indicators of educational production, as the school in Zeeland, with the high favorable environment (99.5\%), has very high national examination grades and student attainment, followed by the school in Overijssel (most favorable environment, 100\%), the school in Noord-Holland (moderate environment, about 98\%) and the school in Amsterdam (least favorable environment $81 \%$ ). Most disadvantaged students are located in the
Randstad region (conurbation; urban agglomeration of Western Holland), of which the school in Noord-Holland and Amsterdam are a part. These are also the most urban regions while the other two schools are located in more rural areas.

The school in Zeeland, with a high favorable environment had declining productivity for all years. This is also true for the school in Amsterdam with the low favorable environment (except for 2002). The EMPI is higher in almost all years for the school in Noord-Holland with the moderate favorable environment and the school in Overijssel with the most favorable environment. From 2006 to 2007, productivity improved by $18.1 \%$ for the school with the most favorable environment and by $8.9 \%$ for the moderate environment school. The school with the most favorable environment saw a decline in productivity of $3.2 \%$ while the school with the harshest environment realized a decline of $6.1 \%$. The detailed results of the four schools with varying environmental harshness show similar results as Table 2, as a moderate share of disadvantaged students experienced more productivity improvements. For schools with a large share of disadvantaged students it seems to be very hard to increase productivity. 
Table 3

Application to specific schools.

\begin{tabular}{|c|c|c|c|c|c|}
\hline & $2002-2003$ & 2003-2004 & 2004-2005 & 2005-2006 & $2006-2007$ \\
\hline \multicolumn{6}{|c|}{ School with most favorable environment - Overijssel } \\
\hline EMPI & 0.982 & 1.037 & 0.976 & 0.974 & 1.181 \\
\hline Efficiency change & 1.040 & 0.987 & 1.050 & 0.954 & 0.997 \\
\hline Technical change & 0.995 & 1.000 & 0.973 & 1.006 & 1.068 \\
\hline Technical change MFE & 0.995 & 1.000 & 0.973 & 1.006 & 1.032 \\
\hline Change in env. harshness & 1.000 & 1.000 & 1.000 & 1.000 & 1.035 \\
\hline Scale efficiency change & 0.949 & 1.051 & 0.955 & 1.014 & 1.110 \\
\hline \multicolumn{6}{|c|}{ School with high favorable environment - Zeeland } \\
\hline EMPI & 0.992 & 0.969 & 0.996 & 0.952 & 0.968 \\
\hline Efficiency change & 0.996 & 0.992 & 1.020 & 0.991 & 0.969 \\
\hline Technical change & 0.999 & 0.993 & 0.976 & 1.004 & 1.026 \\
\hline Technical change MFE & 0.997 & 0.993 & 0.985 & 0.999 & 1.020 \\
\hline Change in env. harshness & 1.002 & 1.000 & 0.991 & 1.005 & 1.005 \\
\hline Scale efficiency change & 0.997 & 0.984 & 1.000 & 0.958 & 0.974 \\
\hline \multicolumn{6}{|c|}{ School with moderate favorable environment - Noord-Holland } \\
\hline EMPI & 1.015 & 1.031 & 0.968 & 0.968 & 1.089 \\
\hline Efficiency change & 0.999 & 1.000 & 0.994 & 0.967 & 1.012 \\
\hline Technical change & 0.998 & 1.006 & 0.997 & 1.005 & 1.041 \\
\hline Technical change MFE & 0.997 & 1.003 & 0.997 & 1.005 & 1.005 \\
\hline Change in env. harshness & 1.001 & 1.003 & 1.000 & 1.000 & 1.036 \\
\hline Scale efficiency change & 1.019 & 1.026 & 0.977 & 0.996 & 1.034 \\
\hline \multicolumn{6}{|c|}{ School with low favorable environment - Amsterdam } \\
\hline EMPI & 1.009 & 0.936 & 0.984 & 0.953 & 0.939 \\
\hline Efficiency change & 1.000 & 1.000 & 1.000 & 1.000 & 1.000 \\
\hline Technical change & 0.995 & 0.833 & 1.183 & 1.251 & 0.788 \\
\hline Technical change MFE & 0.998 & 1.003 & 0.996 & 0.998 & 1.008 \\
\hline Change in env. harshness & 0.997 & 0.831 & 1.188 & 1.253 & 0.781 \\
\hline Scale efficiency change & 1.014 & 1.124 & 0.831 & 0.762 & 1.193 \\
\hline
\end{tabular}

\section{Conclusion and discussion}

In this paper we developed a public sector Malmquist productivity index useful for production environments characterized by nondiscretionary inputs. Johnson and Ruggiero (2011) showed how the environment can influence productivity measures. Their model assumed constant returns to scale. In this paper, we extended their approach to further decompose the Malmquist productivity index into technical, efficiency, scale and environmental change. The decomposition allows an analysis of changes under the assumption that a given production unit faces the most favorable environment under variable returns to scale. We applied our model to analyze productivity of Dutch schools using 2002-2007 data. The results indicate that the environment indeed influences the productivity index, as well as the technical, efficiency, scale and environmental change. We see that schools with a moderate classification of environment have the highest productivity numbers. In line with expectations, schools with the worst environment also perform worse and would perform lot better when they would have a different environment.

The main strength of our paper is that we explicitly include environment change in the Malmquist productivity index, apart from technical, efficiency and scale changes. Another strength is the extension of previous methods to the more general variable returns to scale case. We find that the socio-economic environment plays a crucial role in determining productivity and believe this result has important policy implications. While the main focus was methodological, we believe that a useful extension would be to incorporate bootstrapping to test the robustness of our results. Additionally, like most of the literature, we have focused on the Malmquist productivity index. O'Donnell (2012) has provided alternative measures that might be better suited to measuring productivity. One further extension of this paper would be to incorporate the nondiscretionary factors into these alternative productivity measures. Further, we would like to have many more years to apply a Malmquist productivity index, but due to data limitations including a change in the funding of schools this was not possible. However, for the illustrative purposes of the application in this paper, we believe that six years are sufficient.

With this paper, we add to the large literature in public education, which shows that socio-economic variables including poverty, income and parental education levels have a large and significant effect on the transformation of discretionary inputs into desired outcomes. With our application to Dutch secondary education, we show that this is indeed the case. Furthermore, we add to the literature by our further decomposition of the Malmquist productivity index into technical, efficiency, scale and environmental change. Lastly, another contribution is the implication of these results for schools. Future studies explicitly taking into account the environment, could, for example, lead to completely different rankings (see introduction). This also holds for national rankings of secondary schools, such as the yearly ranking in newspaper 'Trouw' in the Netherlands. Changes in these rankings can have far-reaching consequences for schools, especially the ones with a bad environment, such as higher popularity, both for students choosing the school and for teachers wanting to work for the school.

\section{References}

Afonso, A., \& St. Aubyn, M. (2006). Cross-country efficiency of secondary education provision: A semi-parametric analysis with non-discretionary inputs. Economic Modelling 23 , 476-491.

Banker, R. D. (1984). Estimating most productive scale size using Data Envelopment Analysis. European Journal of Operational Research, 17, 35-44.

Banker, R. D. Charnes, A. \& Cooper, W. (1984). Some models for the estimation of technical and scale efficiencies in Data Envelopment Analysis. Management Science, 30(9), 1078-1092.

Banker, R. D., \& Morey, R. C. (1986a). Efficiency analysis for exogenously fixed inputs and outputs. Operations Research, 34(4), 513-521.

Banker, R. D., \& Morey, R. C. (1986b). The use of categorical variables in data envelopment analysis. Management Science, 32, 1613-1627. 
Becker, B. E., \& Luthar, S. S. (2002). Social-emotional factors affecting achievement outcomes among disadvantaged students: Closing the achievement gap. Educational Psychologist, 37(4), 197-214.

Blank, J. L. T., Koot, P. M., \& van Hulst, B. L. (2007a). Basisonderwijs en bureaucratie Een empirisch onderzoek naar de allocatie van middelen in basisscholen. Delft/ Rotterdam: IPSE Studies/ECORYS.

Blank, J. L. T., Koot, P. M., \& van Hulst, B. L. (2007b). Overhead of Onderwijs - Een benchmark van de allocatie van middelen in onderwijsinstellingen voor voortgezet onderwijs. Delft/Rotterdam: IPSE Studies/ECORYS.

Boles, J. N. (1971). The 1130 Farrell efficiency system--Multiple products, multiple factors. Giannini Foundation of Agricultural Economics (February).

Bradford, D., Malt, R., \& Oates, W. (1969). The rising cost of local public services: Some evidences and reflections. National Tax Journal, 22, 185-202.

Caves, D. W., Christensen, L. R., \& Diewert, W. E. (1982). The economic theory of index numbers and the measurement of input, output, and productivity. Econometrica, 50(6), 1393-1414.

Chakraborty, K., Biswas, B., \& Lewis, W. C. (2000). Economies of scale in public education: An econometric analysis. Contemporary Economic Policy, 18(2), 238-247.

Charnes, A., Cooper, W. W., \& Rhodes, E. (1978). Measuring the efficiency of decision making units. European Journal of Operational Research, 2(6), 429-444.

Conroy, S. J., \& Arguea, N. M. (2008). An estimation of technical efficiency for Florida Public elementary schools. Economics of Education Review, 27, 655-663.

De Witte, K., Rogge, N., Cherchye, L., \& van Puyenbroeck, T. (2012). Economies of scope in research and teaching: A non-parametric investigation. Omega International Journal of Management Science, 41(2), 305-314.

Dijkgraaf, E., van der Geest, S. A., \& de Jong, J. M. (2008). Effect van concurrentie op de kwaliteit van het HAVO en VWO. Rotterdam: SEOR.

Essid, H., Ouellette, P., \& Vigeant, S. (2013). Small is not that beautiful after all: Measuring the scale efficiency of Tunisian high schools using a DEAbootstrap method. Applied Economics, 45(9), 1109-1120.

Essid, H., Ouellette, P., \& Vigeant, S. (2014). Productivity, efficiency, and technical change of Tunisian schools: A Bootstrapped Malmquist approach with quasifixed inputs. Omega, 42, 88-97.

Färe, R. S., \& Grosskopf, S. (1985). A nonparametric cost approach to scale efficiency. Scandinavian Journal of Economics, 87(4), 594-604.

Färe, R. S., Grosskopf, S., Lindgren, B., \& Roos, P. (1992). Productivity changes in Swedish Pharmacies 1980-1989: A non-parametric Malmquist approach. Journal of Productivity Analysis, 3, 85-101.

Färe, R. S., Grosskopf, S., Norris, M., \& Zhang, Z. (1994). Productivity growth technical progress, and efficiency change in industrialized countries. American Economic Review, 84, 66-83.

Färe, R. S., \& Lovell, C. A. K. (1978). Measuring the technical efficiency of production. Journal of Economic Theory, 19, 150-162.

Farrell, M. J. (1957). The measurement of productive efficiency. Journal of the Royal Statistical Society, Series A (General), 120(3), 253-290.

Farrell, M. J., \& Fieldhouse, M. (1962). Estimating efficient productions functions under increasing returns to scale. Journal of the Royal Statistical Society, Series A (General) (125), 252-267.

Gaziel, H. H. (1997). Impact of school culture on effectiveness of secondary schools with disadvantaged students. The Journal of Educational Research, 90(5), 310-318.

Grosskopf, S., Hayes, K. J., \& Taylor, L. L. (2009). The relative efficiency of charter schools. Annals of Public and Cooperative Economics, 80(1), 67-87.

Grosskopf, S., Hayes, K. J., Taylor, L. L., \& Weber, W. L. (1997). Budget-constrained frontier measures of fiscal equality and efficiency in schooling. Review of Economics and Statistics, 79(1), 116-124.

Haelermans, C. (2012). On the productivity and efficiency of education - The role of innovations in Dutch secondary education. Maastricht: Maastricht University.

Haelermans, C., \& Blank, J. L. T. (2012). Is a schools' performance related to educational change? - A study on the relation between innovations and secondary school productivity. Computers and Education, 59(3), 884-892.

Haelermans, C., \& De Witte, K. (2012). The role of innovations in secondary school efficiency: Evidence from a conditional efficiency model. European Journal of Operational Research, 223, 541-549.

Haelermans, C., De Witte, K., \& Blank, J. L. T. (2012). On the allocation of resources for secondary schools. Economics of Education Review, 31(5), 575-586.
Haelermans, C., \& Ruggiero, J. (2013). Estimating technical and allocative efficiency in the public sector: A nonparametric analysis of Dutch schools. European Journal of Operational Research, 227(1), 174-181.

Hanushek, E. A. (1979). Conceptual and empirical issues in the estimation of education production functions. Journal of Human Resources, 14, 351-388.

Hanushek, E. A. (1986). The economics of schooling: Production and efficiency in public schools. Journal of Economic Literature, XXIV, 1141-1171.

Hoxby, C. M. (2004). Productivity in education: The quintessential upstream industry. Southern Economic Journal, 71(2), 208-231.

Izadi, H., Johnes, G., Oskrochi, R., \& Crouchley, R. (2002). Stochastic Frontier Estimation of a CES cost function: The case of higher education in Britain. Economics of Education Review, 21, 63-71.

Johnes, J., Bradley, S., \& Little, A. (2012). Efficiency in the further education sector in England. Open Journal of Statistics, 2, 131-140.

Johnson, A. L., \& Ruggiero, J. (2011). Nonparametric measurement of productivity and efficiency in education. Annals of Operations Research.

Joumady, O., \& Ris, C. (2005). Performance in European higher education: A non-parametric production frontier approach. Education Economics, 13(2) 189-205.

Kempkes, G., \& Pohl, C. (2008). Do institutions matter for university cost efficiency? Evidence from Germany. Ifo Institute for Economic Research.

Kirjavainen, T., \& Loikkanen, H. A. (1998). Efficiency differences of Finnish senior secondary schools: An application of DEA and Tobit analysis. Economics of Education Review, 17(4), 377-394.

Mancebón, M.-J., Calero, J., Choi, A., \& Ximénez-de-Embún, D. P. (2012). The efficiency of public and publicly subsidized high schools in Spain: Evidence from PISA-2006. Journal of the Operational Research Society, 63, 1516-1533.

Millimet, D. L., \& Collier, T. (2008). Efficiency in public schools: Does competition matter? Journal of Econometrics, 145, 134-157.

National Centre for Education Statistics. Trends in International Mathematics and Science Study (TIMSS). <http://nces.ed.gov/timss/>.

O'Donnell, C. J. (2011). The sources of productivity change in the manufacturing sectors of the U.S. economy. Center for Efficiency and Productivity Analysis (CEPA) WP07/2011.

O'Donnell, C. J. (2012). Nonparametric estimates of the components of productivity and profitability change in US agriculture. American Journal of Agricultural Economics, 94(4), 873-890.

OECD. Programme for International Student Assessment (PISA). <http:// www.pisa.oecd.org/>.

Oliveira, M. A., \& Santos, C. (2005). Assessing school efficiency in Portugal using FDH and bootstrapping. Applied Economics, 37, 957-968.

Ouellette, P., \& Vierstraete, V. (2005). An evaluation of the efficiency of Québec's school boards using the data envelopment analysis method. Applied Economics, 37, 1643-1653.

Ouellette, P., \& Vierstraete, V. (2010). Malmquist indexes with quasi-fixed inputs: An application to school districts in Québec. Annals of Operations Research, 173 57-76.

Parteka, A., \& Wolszcak-Derlacz, J. (2012). Dynamics of productivity in higher education: Cross-European evidence based on bootstrapped Malmquist indices. Journal of Productivity Analysis, 1-16.

Ray, S. C., \& Desli, E. (1997). Productivity growth, technical progress, and efficiency change in industrialized countries: Comment. American Economic Review, 87, 1033-1039.

Ruggiero, J. (1996a). Efficiency of educational production: An analysis of New York school districts. Review of Economics and Statistics, 78(3), 499-509.

Ruggiero, J. (1996b). On the measurement of technical efficiency in the public sector. European Journal of Operational Research, 90, 553-565.

Ruggiero, J. (1998). Non-discretionary inputs in Data Envelopment Analysis. European Journal of Operational Research, 111, 461-469.

Ruggiero, J. (2000). Nonparametric estimation of returns to scale in the public sector with an application to the provision of educational services. Journal of the Operational Research Society, 51, 906-917.

Ruggiero, J. (2007). Measuring the cost of meeting minimum educational standards: An application of data envelopment analysis. Education Economics, 15(1), 1-13.

Smet, M., \& Nonneman, W. (1998). Economies of scale and scope in Flemish secondary schools. Applied Economics, 30, 1251-1258. 